\title{
Influence of machining parameters on the polymer concrete milling process
}

\author{
Norbert Kepczak $^{1}$ (D) P Piotr Zgorniak ${ }^{1}$ (D) $\cdot$ Paweł Lajmert $^{1}$ (D) $\cdot$ Radoslaw Rosik $^{1}$ (D) $\cdot$ Malgorzata Sikora ${ }^{1}$ (I)
}

Received: 1 July 2019 / Accepted: 9 December 2019 / Published online: 2 January 2020

(C) The Author(s) 2020

\begin{abstract}
The paper examines the wear of end mill cutters, the parameters of a workpiece's surface layer and the values of cutting forces during the machining of polymer concrete, which is one of the most difficult-to-cut materials. Increased abrasive wear of the active cutting edges is a result of the heterogeneous structure of this material, and it has a negative effect on the cutting process, the durability of the cutting tools as well as the roughness of the workpiece. It is very important to determine the machining parameters for this material from a tool durability and quality of machining point of view. The research was divided into two stages. In the first stage, the appropriate machining parameters were determined based on the measurement of the components of the cutting force. In the second stage, durability tests of four end mill cutters were carried out. During the tests, the component cutting forces, tool wear and surface roughness were measured. The highest tool durability was recorded for the monolithic cemented carbide cutter with coating NC Mill G9F42120N 4F. Tools made of high-speed steel should not be used for machining polymer concrete, as they exhibited the highest intensity of tool wear. The rapid loss of machinability of these tools leads to a rapid increase in cutting force and the roughness of the machined surface. From an economic point of view, cemented carbide end mill cutters with coatings seem to be the appropriate choice for machining polymer concrete.
\end{abstract}

Keywords Milling $\cdot$ Polymer concrete $\cdot$ Mineral cast $\cdot$ Wear $\cdot$ Surface roughness $\cdot$ Cutting forces

$\begin{array}{ll}\text { Nomenclature } \\ \boldsymbol{v}_{\boldsymbol{c}} \quad \text { cutting speed } \\ \boldsymbol{v}_{\boldsymbol{f}} \quad \text { table feed } \\ \boldsymbol{a}_{\boldsymbol{p}} \quad \text { axial depth of cut } \\ \boldsymbol{a}_{\boldsymbol{e}} & \text { radial depth of cut }\end{array}$

Norbert Kepczak

norbert.kepczak@p.lodz.pl

Piotr Zgorniak

piotr.zgorniak@p.lodz.pl

Paweł Lajmert

pawel.lajmert@p.lodz.pl

Radoslaw Rosik

radoslaw.rosik@p.lodz.pl

Malgorzata Sikora

malgorzata.sikora@p.lodz.pl

1 Institute of Machine Tools and Production Engineering, Faculty of Mechanical Engineering, Lodz University of Technology,

Stefanowskiego 1/15, 90-924 Lodz, Poland
$\boldsymbol{F}_{\boldsymbol{x}} \quad$ component cutting force in X direction of the rotating dynamometer

$\boldsymbol{F}_{\boldsymbol{y}}$ component cutting force in Y direction of the rotating dynamometer

$\boldsymbol{F}_{\boldsymbol{z}} \quad$ component cutting force in axial $\mathrm{Z}$ direction of the rotating dynamometer

$\boldsymbol{F}_{\boldsymbol{a}} \quad$ resultant active force in the $\mathrm{X}-\mathrm{Y}$ plane

$\boldsymbol{L} \quad$ cutting distance

$\boldsymbol{R} \boldsymbol{a}$ roughness average

$\boldsymbol{R} \boldsymbol{z} \quad$ average maximum height of the profile

$\boldsymbol{V B 1}$ uniform flank wear

$\boldsymbol{V B 2}$ non-uniform flank wear

\section{Introduction}

Modern industry is constantly looking for new construction solutions, as well as modern and ecological materials, which thanks to their properties will improve the quality of manufactured products, reduce the costs associated with the production process and increase its flexibility. Such materials include polymer concrete, which also appears under the name 
mineral cast. It is a complex material consisting of inorganic aggregates, such as basalt, spodumene $\left(\mathrm{LiAlSi}_{2} \mathrm{O}_{6}\right)$, fly ash, river gravel, sand, chalk, etc., bound with each other by resin [1-3]. The most commonly used resins are epoxy [4], polyester [5] and vinyl ester [6].

Current trends in the development of machine tool construction include the application of mineral casts as substitutes for cast iron. In some cases, polymer concrete is applied to selected components of machine tools, e.g. guides or as filler for the ribs of machine tool bodies [7]. This material is also used to manufacture entire machine tool frames, e.g. precision grinding machine bodies, if the strength requirements allow $[8,9]$. What is more, in order to improve the dynamic properties of machine tool, polymer concrete with addition of styrene-butadiene rubber can be used [10].

Due to the significant initial dimensional and shape errors of mineral cast, it is necessary to carry out precise machining in selected surfaces of the material for the correct assembly of machine tool parts. For this purpose, the most widely used method is milling.

The literature offers mostly information on turning $[11,12]$ or grinding [13-15] mineral casts. The results of these tests, however, have no impact on the milling process due to the variability of the cutting edge loads occurring during this process. Variable cutting edges loads adversely affect tool durability, dimensional and shape accuracy, the quality of the machined surface and the cost of machining. Therefore, it was considered reasonable to determine the durability of tools during the milling of polymer concrete. It was very important to select the appropriate machining conditions and cutting tool, both of which are known to influence considerably the course and effects of the machining process of polymer concrete.

Modern high-performance tools, which allow high-speed cutting, have had a significant impact on the development of machining. The increase in durability of cutting tools depends on the abrasive resistance of the material from which they are made (high-speed steel, cemented carbide, ceramics or superhard materials - cubic boron nitride ( $\mathrm{CBN})$ or synthetic diamond) [16]. In the case of polymer concrete processing, due to its heterogeneity, durability of the tool can be a parameter determining its application.

Cutting edge wear refers to the geometric change of the tool during operation and is related to material loss, change of deformation, high temperature, etc. Mechanical wear can occur after exceeding the immediate or fatigue strength of the cutting edge. It may have an unexpected character and is often called strength wear, which can be manifested by nicks at the edge of the cutting tool, chipping, breaks or cracks. The vibrations of the tool relative to the workpiece are one of the reasons for strength wear. Abrasive wear is caused by micro-scratching and shearing of micro-tops and irregularities on the surface of the active cutting edge. Typical abrasive wear is characterized by loss, cracks, plastic deformation or oxidation of the material.
The degree of the tool's wear is described by wear indicators, which are determined on the flank and face surfaces. These indicators are described in detail in works [12, 17]. When the cutting properties of the edge are lost due to tool wear, 'dulling' occurs.

Failure to comply with technological criteria may lead to weakening and excessive wear of the cutting tool, resulting in catastrophic tool wear. The recommended values of wear criteria for fine machining are shown in Table 1 [18].

Monitoring the varying conditions of milling tools over time to facilitate the timely detection of tool damage is critical for limiting the indirect effects of tool breakage while maximizing the usable life of milling tools. Thus, tool condition monitoring (TCM) systems have been developed to generate better workpiece surface quality and extend tool life by diagnosing cutting tool deficiencies using appropriate signal processing and pattern recognition techniques. An accurate and reliable TCM system can reduce costs by $10-40 \%$ by reducing downtime and maximizing the usable life of milling tools [19, 20]. Monitoring the machining process in real time allows for the uninterrupted monitoring of process conditions during cutting without the need to stop the machine in order to measure tool wear, cutting forces, surface roughness, etc. [21]. Various real-time monitoring instruments exist, such as dynamometers, current sensors, vibrations sensors and acoustic emissions [22-24].

During milling processes, tool wear increases surface roughness and leads to a corresponding increase in cutting force. A number of studies [25-28] have demonstrated that the cutting force is very sensitive to changes in tool condition and can, therefore, accurately estimate the state of the tool. Wang et al. [29] determined that the cutting force signal is the most stable and reliable signal among the commonly employed sensor signals closely related to tool wear. Huang et al. [30] used a piezoelectric dynamometer to monitor the tool state of an end milling operation according to cutting force. Bulent et al. [31] adopted a rotary dynamometer to capture the cutting forces in three dimensions and the torque of the drive moment on a rotating tool. Cutting force sensors, however, are difficult to apply in industrial environments because their physical properties limit the physical size of a workpiece, which is not practical when milling medium and large workpieces [32]. In addition, Koike et al. [33]

Table 1 Recommended values of the wear criteria of milling tools [18]

\begin{tabular}{lccc}
\hline Material of cutters & \multicolumn{4}{l}{ Indicator of wear [mm] } \\
\cline { 2 - 4 } & $V B 1$ & $V B 2$ & $K T$ \\
\hline High-speed steel & $0.2-1.0$ & $0.35-1.0$ & $0.1-0.7$ \\
Cemented carbide & $0.3-0.5$ & $0.5-0.7$ & $0.1-0.2$ \\
Ceramics & $0.15-0.3$ & - & 0.1 \\
\hline
\end{tabular}


established that cutting force monitoring interferes with the motion control of the spindle and stage in a milling machine, thus, reducing its rigidity. Moreover, the expense of commercial dynamometers can increase manufacturing costs prohibitively [34, 35].

This article presents the results of investigations on the polymer concrete milling process. The study has been divided into two stages. In the first stage, convenient processing parameters for polymer concrete were determined on the basis of cutting force. In the second stage, durability tests of four end mill cutters were carried out. In order to obtain a full picture of the cutting process during machining, the values of the components of cutting force were recorded. Then, following machining, tool wear and the roughness of the machined surface were measured. A schematic diagram of the experimental setup showing the procedures used during the investigation can be found in Fig. 1.

\section{Materials and methods}

The material used for the tests was polymer concrete offered by RAMPF, available on the market under the name EPUCRET 140/5 [36]. This is a material used for casting small parts of machines, for example, guideways, tables or beds, with a weight not exceeding $500 \mathrm{~kg}$. It consists of aggregates with dimensions ranging from a few micrometres up to $5 \mathrm{~mm}$. A series of cuboidal samples were prepared for the tests with the following dimensions: cross-section $40 \times 40 \mathrm{~mm}$ and height $60 \mathrm{~mm}$. The samples were prepared according to the following composition:

- $10 \%$ weight of the resin with the hardener

- $50 \%$ weight of grains, with grain diameter not exceeding $2 \mathrm{~mm}$

- $40 \%$ weight of grains, with grain diameter greater than $2 \mathrm{~mm}$

Figure 2 shows a view of a sample prepared for testing, mounted on a machine vice.

The purpose of the first part of the study was to determine the appropriate cutting parameters by performing milling tests with variable machining parameters: cutting speed $\left(v_{c}\right)$, table feed $\left(v_{f}\right)$ and axial depth of cut $\left(a_{p}\right)$, and analysing the cutting force components. In the scientific literature, there is no information on the machining parameters during the milling of mineral casts. Therefore, the intention of these experiments was to determine the most convenient cutting parameters in order to obtain the smallest values for the cutting force components. For this research, monolithic cemented carbide end mill cutter NC Mill G9F42120N with coating, with a diameter of $12 \mathrm{~mm}$, was used (Fig. 3c). During each test, a new cutter was mounted on the machine. The cutting distance during the machining of polymer concrete was $L=60 \mathrm{~mm}$. Milling tests were repeated three times. The research was conducted on a Haas Mini Mill CNC milling machine with a spindle power of $7.5 \mathrm{~kW}$. Based on the machine tool capabilities, the tests were carried out for three cutting speed values $v_{c}$, three table feed

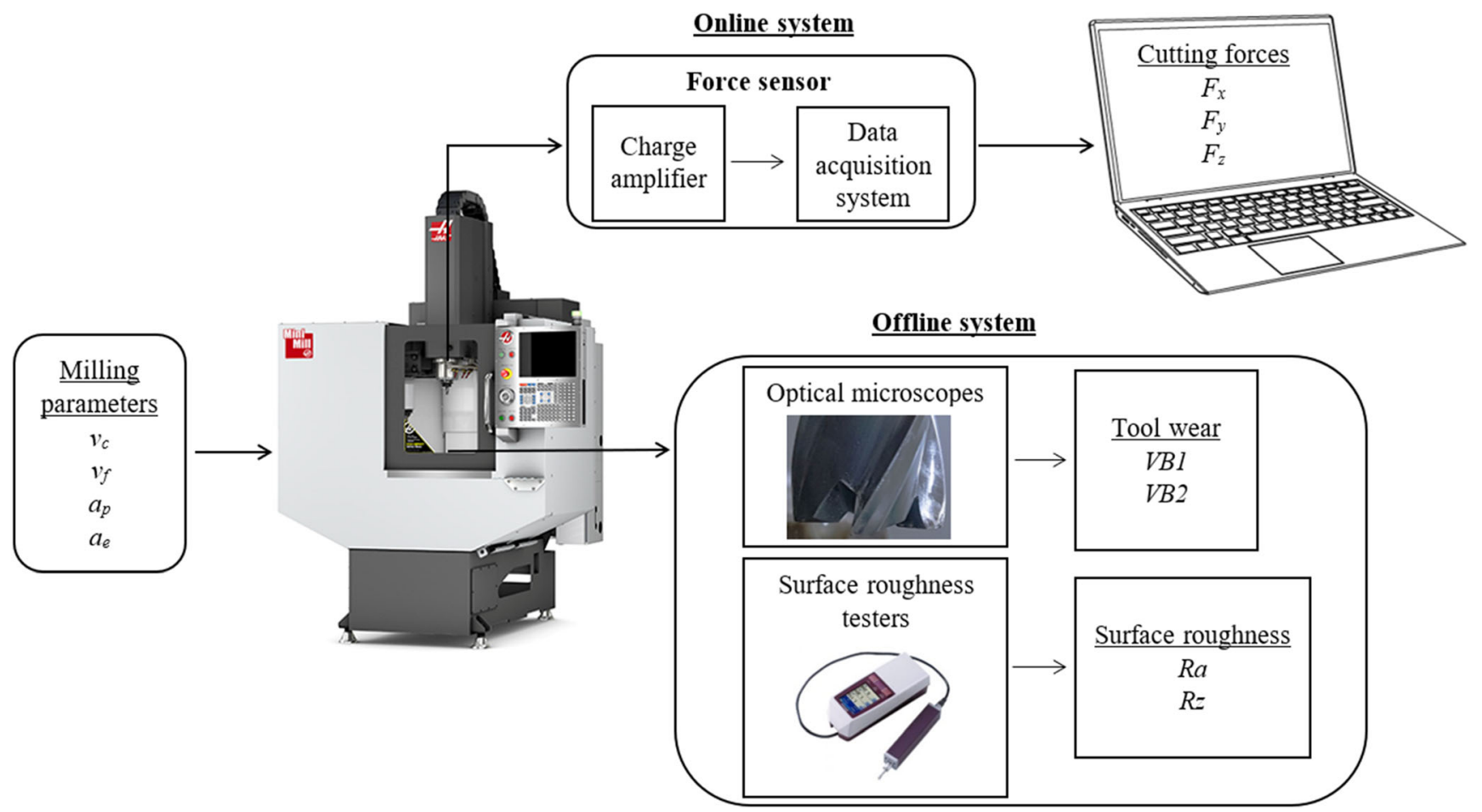

Fig. 1 Schematic diagram of experimental setup showing the procedures used during the investigation 


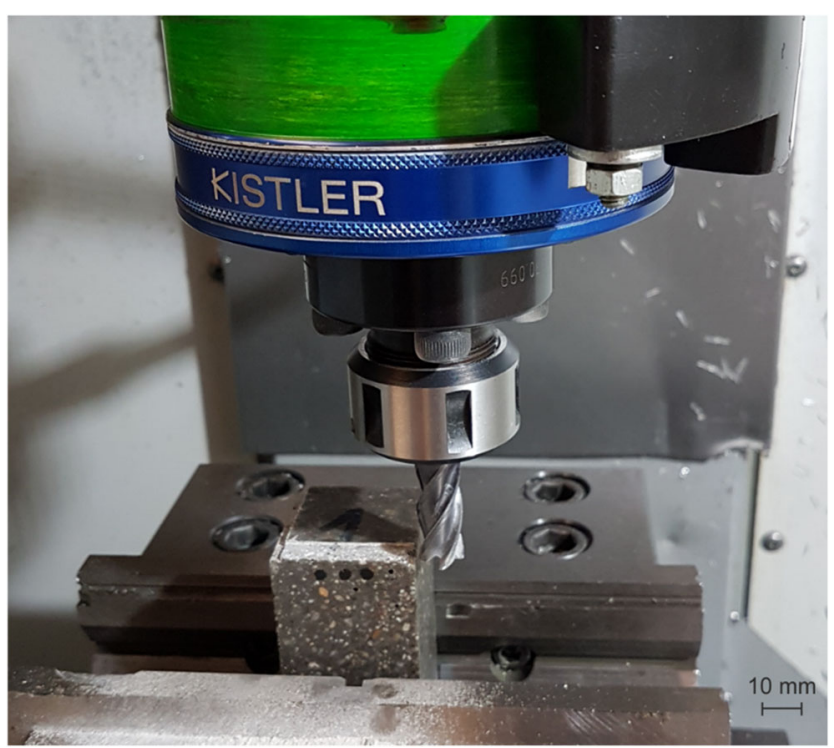

Fig. 2 Machined sample with NC Mill G9F42120N 4Fend mill cutter

values $v_{f}$ and three cutting axial depth values $a_{p}$ (Table 2). The value of radial depth of cut $a_{e}$ was constant and set at $8 \mathrm{~mm}$. A Kistler type $9123 \mathrm{C}$ rotary dynamometer was used for the tests, which was connected to a Kistler 5223 type amplifier. Data from the dynamometer was registered by Keithley KUSB3102 data acquisition card and quickDAQ measuring software.

In the second part of the study, experiments on the wear of four end mill cutters with a diameter of $12 \mathrm{~mm}$ of various construction materials were carried out (Fig. 3):

a) Monolithic cutter HSS Fenes 844 A $12 \mathrm{~K}-\mathrm{N} ; z=4$; helix angle $\lambda=30^{\circ}$; rake angle $=8^{\circ}$

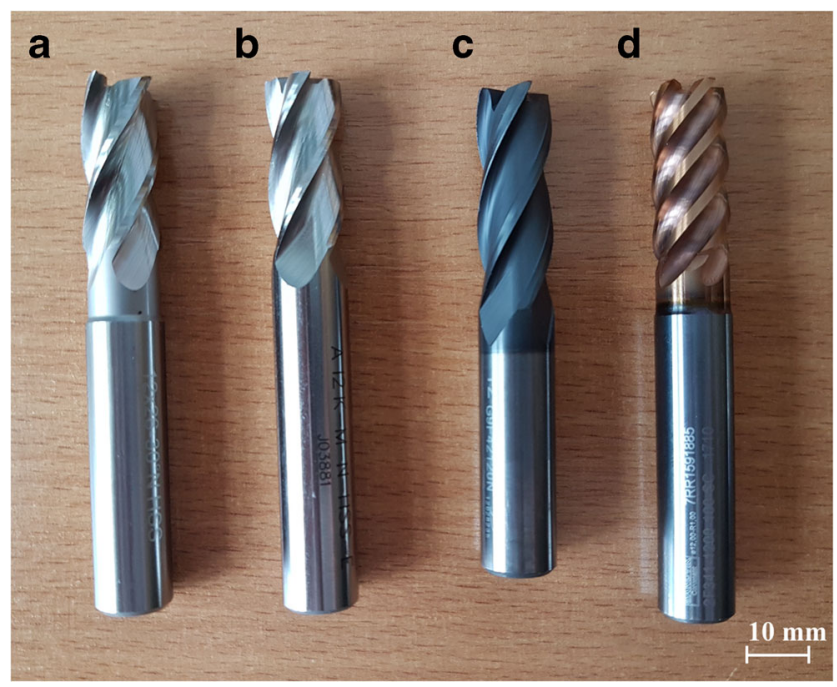

Fig. 3 Tools used in the experiments: (a) HSS Fenes 844 A12K-N, (b) Dolfamex A12 K-M-N HSS-E, (c) NC Mill G9F42120N 4F, (d) Sandvick Coromant 2F341-1200-100-SC 1710 b) Monolithic cutter with addition of cobalt Dolfamex DIN844A 12 K-M-N HSS-E; $z=4$; helix angle $\lambda=30^{\circ}$; rake angle $=8^{\circ}$

c) Monolithic cemented carbide cutter with coating YG-1 Group; Nc Mill G9F42120N 4F; $z=4$; helix angle $\lambda=$ $30^{\circ}$; micrograin, X-Coating

d) Monolithic cemented carbide cutter with protective coating Sandvik 2F341-1200-100-SC 1710; $z=5$; helix angle $\lambda=42^{\circ}$; grade, 1710 ; coating, PVD TiAlN+TiSiN; corner radius $=1 \mathrm{~mm}$; axial rake angle $=10.5^{\circ}$

In order to obtain reliable cutting test results, each milling test presented in Table 2 was repeated three times. For the final evaluation of the influence of individual cutting parameters and the type of cutting tool, the results were developed using mathematical statistics. In addition, for each test, the parameters describing the microgeometry of the machined surface were measured using the Mitutoyo SJ-210 surface roughness gauge. The arithmetic mean of three measurements of $R a$ and $R z$ surface roughness parameters was calculated for each sample in strictly defined places in order to define the influence of the wear of cutters on surface quality.

\section{Experimental results}

\subsection{Selection of appropriate cutting parameters}

The initial examination concerned $F_{x}, F_{y}$ and $F_{z}$ component forces acquired with $1000 \mathrm{~Hz}$ frequency. The influence of depth of cut $a_{p}$, table feed $v_{f}$ and cutting speed $v_{c}$ on cutting forces during the polymer concrete milling process was investigated. The values of component forces $F_{x}$ and $F_{y}$ have been located approximately symmetrically in accordance with level zero [37]. For better evaluation results, the $F_{a}$ resultant active force in the $\mathrm{X}-\mathrm{Y}$ plane has been calculated as the root of the sum of component squares $F_{x}$ and $F_{y}(1)$.

$F_{a}=\sqrt{F_{x}^{2}+F_{y}^{2}}$

A representative resultant active force profile obtained in test 1 (Table 2) is presented in Fig. 4.

For cutting test 7, where the fastest table feed $v_{f}=300 \mathrm{~mm} /$ min was set, the total number of samples acquired was 13,632. This test determined the evaluating range of 10,001 samples for all cutting tests, which gives approximately $10 \mathrm{~s}$ of evaluated time. On the basis of the described procedure, the influence of different cutting parameters on resultant active force $F_{a}$ has been investigated. The results of the influence of depth of cut $a_{p}$, table feed $v_{f}$ and cutting speed $v_{c}$ on $F_{a}$ have been presented in Fig. 5. 
Table 2 Machining parameters

\begin{tabular}{lllll}
\hline Test & $\begin{array}{l}\text { Cutting speed } \\
v_{c}[\mathrm{~m} / \mathrm{min}]\end{array}$ & $\begin{array}{l}\text { Table feed } \\
v_{f}[\mathrm{~mm} / \mathrm{min}]\end{array}$ & $\begin{array}{l}\text { Axial depth of cut } \\
a_{p}[\mathrm{~mm}]\end{array}$ & $\begin{array}{l}\text { Radial depth of cut } \\
a_{e}[\mathrm{~mm}]\end{array}$ \\
\hline 1 & 25 & 100 & 1 & 8 \\
2 & 25 & 100 & 2 & \\
3 & 25 & 100 & 3 & \\
4 & 50 & 200 & 1 & \\
5 & 25 & 200 & 1 & \\
6 & 15 & 200 & 1 & \\
7 & 25 & 300 & 1 & \\
\hline
\end{tabular}

In each box, the central mark indicates the median, and the bottom and top edges of the box indicate the 25th and 75th percentiles, respectively. The whiskers extend to the most extreme data points that are not considered outliers (lower and upper adjacent), while the outliers are plotted individually using the ' + ' symbol. The detailed results of $F_{a}$ forces presented in Fig. 5 have been tabulated in Table 3.

On the basis of the obtained results presented in Fig. 5 and Table 3, an increase of the $F_{a}$ force alongside the increase of depth of cut $a_{p}$ was observed. $F_{a}$ force also increased alongside table feed $v_{f}$. When cutting speed $v_{c}$ increased, however, $F_{a}$ values initially decreased and raised their minimum at $25 \mathrm{~m} / \mathrm{min}$. Then, the values of $F_{a}$ increased again.

The same procedure was employed for the $F_{z}$ component cutting force. Evaluation took place on the same number of samples as for the resultant active force $F_{a}$. The influence of different cutting parameters on $F_{z}$ component forces was presented in Fig. 6.

The detailed results of $F_{z}$ forces presented in Fig. 6 have been tabulated in Table 4.

The obtained data of component cutting force $F_{z}$ have similar character to resultant active force $F a$, which confirms the authors' selection of cutting parameters for the following tests.
Although the data presented on the basis of raw signals shows correctly the influence of different types of cutting parameters, the authors decided to use a special script created in MATLAB taking into consideration the moving average (movmean) and also a function called "findpeaks". By means of this script, it was possible to analyse the influence of different values of parameters, such as window size in the moving average and also the distance between peaks in the course of forces. Peaks in the signal seem to appear at regular intervals. Some of the peaks, however, are very close to each other. The MinPeakProminence property was used to filter out these peaks. For better clarity, Fig. 7 presents the results of filtering the $F_{z}$ signal by moving average, with a window parameter equal to 100 and the MinPeakProminence parameter set to 4 . In order to identify the maximum force values recorded during the milling process, the mean of maximum values for $F_{a}$ and $F_{z}$ was employed (Figs. 11 and 12) and a longer time interval was taken into consideration during tool wear investigation (Chapter 4.2.2).

Based on the analyses carried out for the milling tests, it can be observed that minimum values of component forces were obtained in tests 1, 6 and 7. Conversely, maximum values were obtained in test 3 (Table 2). As is well known, extensive levels
Fig. 4 Raw signal of resultant active force $F_{a}$ obtained for test number 1 presented in Table 2

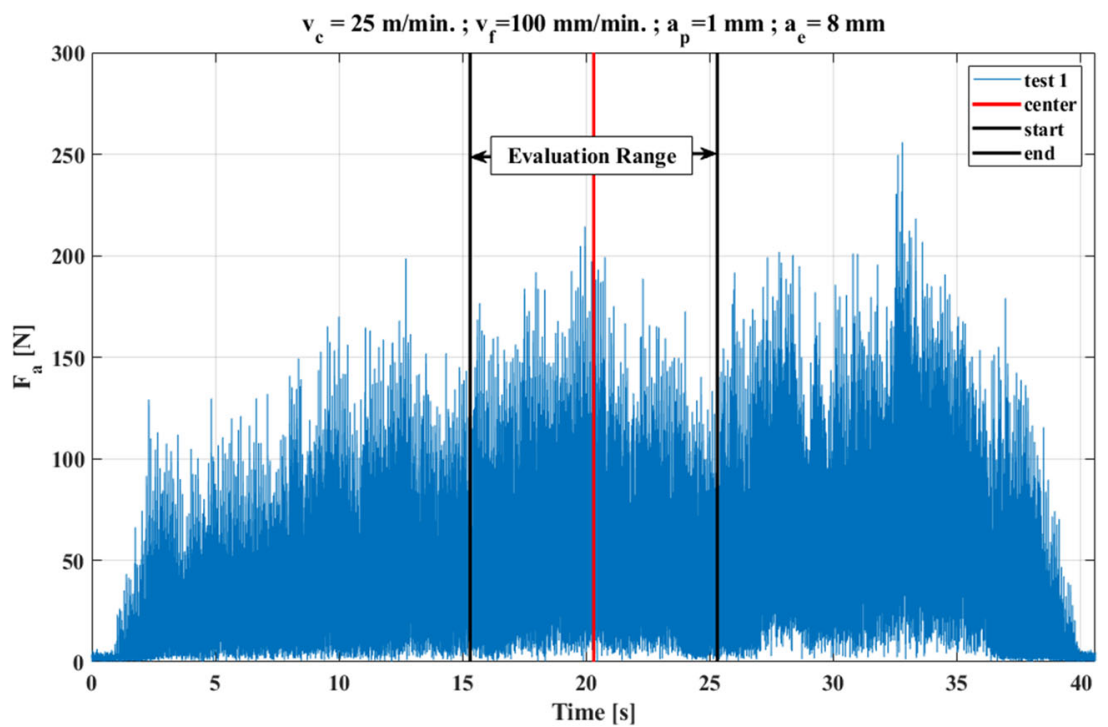


Fig. 5 Boxplots of the influence of cutting parameters on resultant active force $F_{a}$

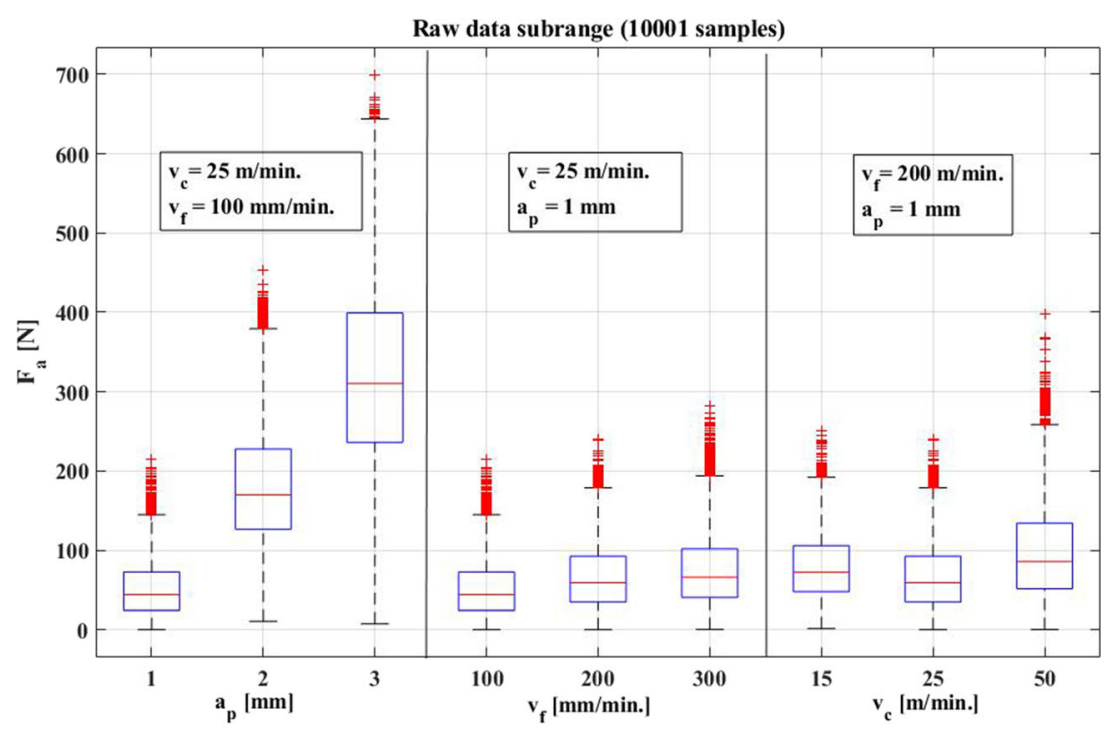

of cutting force during removal processes cause accelerated wear in cutting tools and tool-in-use systems of machine tools.

On the basis of the obtained results, the authors concluded that for tool-life tests, the following parameters should be established: $a_{p}=1 \mathrm{~mm}, v_{f}=100 \mathrm{~mm} / \mathrm{min}$ and $v_{c}=25 \mathrm{~m} / \mathrm{min}$.

\subsection{Tool-life testing}

The method for measuring wear indicators in the case of end mill cutters is more complicated than in the case of the turning process [38]. Various designations for these indicators can be found in the literature $[12,17,39]$. During the machining of polymer concrete, the most common wear type observed is abrasive wear on the tool flank of the end mill cutter. In order to evaluate the intensity of abrasive wear of different types of end mill cutters (Fig. 3), two categories of wear indicators have been chosen [39]:

- $\quad V B 1$ - uniform flank wear

- $V B 2$ - non-uniform flank wear
Machining tests of cuboid samples with cutting speed $v_{c}=25 \mathrm{~m} / \mathrm{min}$, table feed $v_{f}=100 \mathrm{~mm} / \mathrm{min}$, axial depth of cut $a_{p}=1 \mathrm{~mm}$ and radial depth of cut $a_{e}=8 \mathrm{~mm}$ were carried out. The total milling distance for each tool depended on its degree of wear. If extensive tool wear was observed, exceeding the recommended values, or if chipping had occurred, the experiment was interrupted because the tool was unable to continue with the machining operation. In this article, the non-uniform flank wear indicator VB2 was determined from the flank and concerned the maximum value detected after each cutting test. The uniform flank wear indicator VB1 was determined from the cylindrical flank as an average of three measurements from a relatively uniform abrasive wear area. An indicative way of measuring the described indicators is presented in Fig. 8. The values of indicators presented in the subsequent plots are the arithmetic mean of wear measured on all teeth of the milling cutters tested.

Table 3 Detailed results of $F_{a}$ forces

\begin{tabular}{|c|c|c|c|c|c|c|c|c|c|}
\hline & \multicolumn{3}{|l|}{$a_{p}[\mathrm{~mm}]$} & \multicolumn{3}{|c|}{$v_{f}[\mathrm{~mm} / \mathrm{min}]$} & \multicolumn{3}{|c|}{$v_{c}[\mathrm{~m} / \mathrm{min}]$} \\
\hline & $\underline{1}$ & $\underline{2}$ & $\underline{3}$ & $\underline{100}$ & $\underline{200}$ & $\underline{300}$ & $\underline{15}$ & $\underline{25}$ & $\underline{50}$ \\
\hline Min. & 0.174 & 10.519 & 7.554 & 0.1740 & 0.0738 & 0.440 & 1.415 & 0.074 & 0.266 \\
\hline Lower adjacent & 0.174 & 10.519 & 7.554 & 0.1740 & 0.0738 & 0.440 & 1.415 & 0.074 & 0.266 \\
\hline 25 th percentile & 24.183 & 126.510 & 236.024 & 24.183 & 34.438 & 40.259 & 47.526 & 34.438 & 51.257 \\
\hline Median & 43.785 & 169.759 & 310.262 & 43.785 & 58.794 & 65.707 & 72.095 & 58.794 & 85.355 \\
\hline 75th percentile & 72.470 & 227.573 & 399.096 & 72.471 & 92.285 & 101.756 & 105.605 & 92.285 & 134.208 \\
\hline Upper adjacent & 144.856 & 379.040 & 643.487 & 144.857 & 178.809 & 193.718 & 192.080 & 178.809 & 258.555 \\
\hline Max. & 214.326 & 452.626 & 699.221 & 214.326 & 239.981 & 282.184 & 251.054 & 239.981 & 397.530 \\
\hline Outliers & 156 & 83 & 15 & 156 & 79 & 179 & 68 & 79 & 117 \\
\hline
\end{tabular}


Fig. 6 Boxplots of the influence of cutting parameters on the $F_{z}$ component cutting force

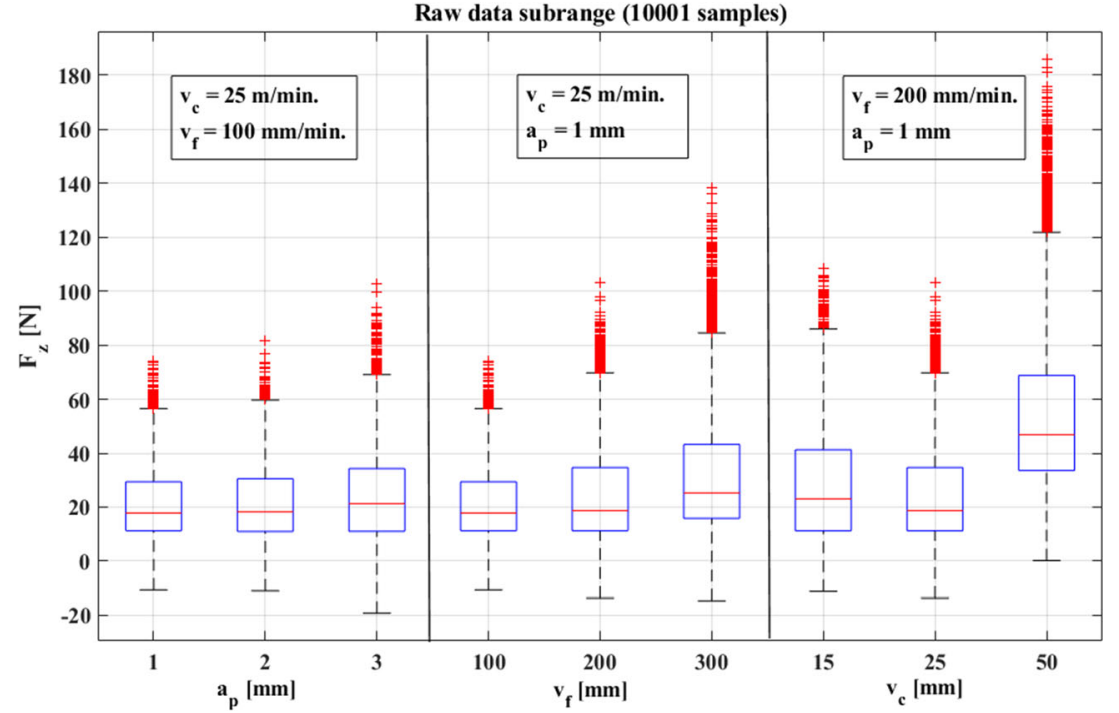

\subsubsection{Wear of end mill cutters}

Figure 9 shows wear indicators $V B 1$ and $V B 2$ as a function of cutting distance $L$, measured in compliance with the procedure described in the previous chapter and illustrated in Fig. 8. The highest wear after the shortest cutting distance was obtained for HSS cutters made of high-speed steel, i.e. 844 A 12 K-N and A 12 K-M-N HSS-E. At the very beginning of the experiment, these mill cutters were heavily worn and were not suitable for further machining. The smallest wear and the longest cutting distance $L$ were obtained for a cemented carbide milling cutter, NC Mill G9F42120N 4F, with protective coating. In this case, a cutting distance of $L=3550 \mathrm{~mm}$ was obtained with the abrasive wear criterion of $V B 1=0.5 \mathrm{~mm}$. The fastest wear was observed at the corners of the tool.

In the initial cutting trials (up to $L=1120 \mathrm{~mm}$ ), the least wear was obtained for the Sandvick Coromant 2F341-1200100-SC 1710 end mill cutter with protective coating. During the tool-life experiment, however, it transpired that the applied coating was not resistant to impact strength, which caused it to break off at a rapid rate and intensive wear. Upon exceeding the cutting distance of $L=1120 \mathrm{~mm}$, considerable nicks appeared on the cutting edges. These tests confirmed that when machining polymer concrete samples, intensive abrasion is observed at the corners and on the cylindrical and front flanks (Fig. 8), making it highly difficult to machine. A very important factor that has a direct impact on the durability of cutting tools is the amount of heat generated in the machining zone. This aspect has been widely studied [40-42]. Based on the literature review, it was found that not only the cutting parameters should be selected in such a way as to obtain the highest efficiency, but also that the temperature values generated in the machining zone should be taken into account. As heat generated during the machining process has a significant impact on the durability of cutting tools, maximum temperature values should be investigated and measured. This is especially important in the case of dry cutting or cutting with a minimum quantity of lubrication (MQL). In the research presented in this article, the flooding method of delivering a coolinglubricant liquid into the cutting zone was employed.

Table 4 Detailed results of $F z$ forces

\begin{tabular}{|c|c|c|c|c|c|c|c|c|c|}
\hline & \multicolumn{3}{|l|}{$a_{p}[\mathrm{~mm}]$} & \multicolumn{3}{|c|}{$v_{f}[\mathrm{~mm} / \mathrm{min}]$} & \multicolumn{3}{|c|}{$v_{c}[\mathrm{~m} / \mathrm{min}]$} \\
\hline & $\underline{1}$ & $\underline{2}$ & $\underline{3}$ & $\underline{100}$ & $\underline{200}$ & $\underline{300}$ & $\underline{15}$ & $\underline{25}$ & $\underline{50}$ \\
\hline Min. & -10.693 & -11.035 & -19.238 & -10.693 & -13.672 & -14.648 & -11.182 & -13.672 & 0.195 \\
\hline Lower adjacent & -10.693 & -11.035 & -19.238 & -10.693 & -13.672 & -14.648 & -11.182 & -13.672 & 0.195 \\
\hline 25 th percentile & 11.279 & 10.986 & 11.035 & 11.279 & 11.231 & 15.820 & 11.279 & 11.231 & 33.594 \\
\hline Median & 17.822 & 18.311 & 21.240 & 17.822 & 18.750 & 25.244 & 23.047 & 18.750 & 46.875 \\
\hline 75th percentile & 29.394 & 30.518 & 34.277 & 29.394 & 34.668 & 43.274 & 41.272 & 34.668 & 68.897 \\
\hline Upper adjacent & 56.543 & 59.766 & 69.141 & 56.543 & 69.824 & 84.424 & 85.938 & 69.824 & 121.777 \\
\hline Max. & 74.072 & 81.641 & 102.734 & 74.072 & 102.979 & 138.477 & 108.301 & 102.979 & 185.938 \\
\hline Outliers & 70 & 52 & 114 & 70 & 150 & 325 & 65 & 150 & 361 \\
\hline
\end{tabular}


Fig. 7 Filtering results of $F_{z}$ component cutting force for test 1

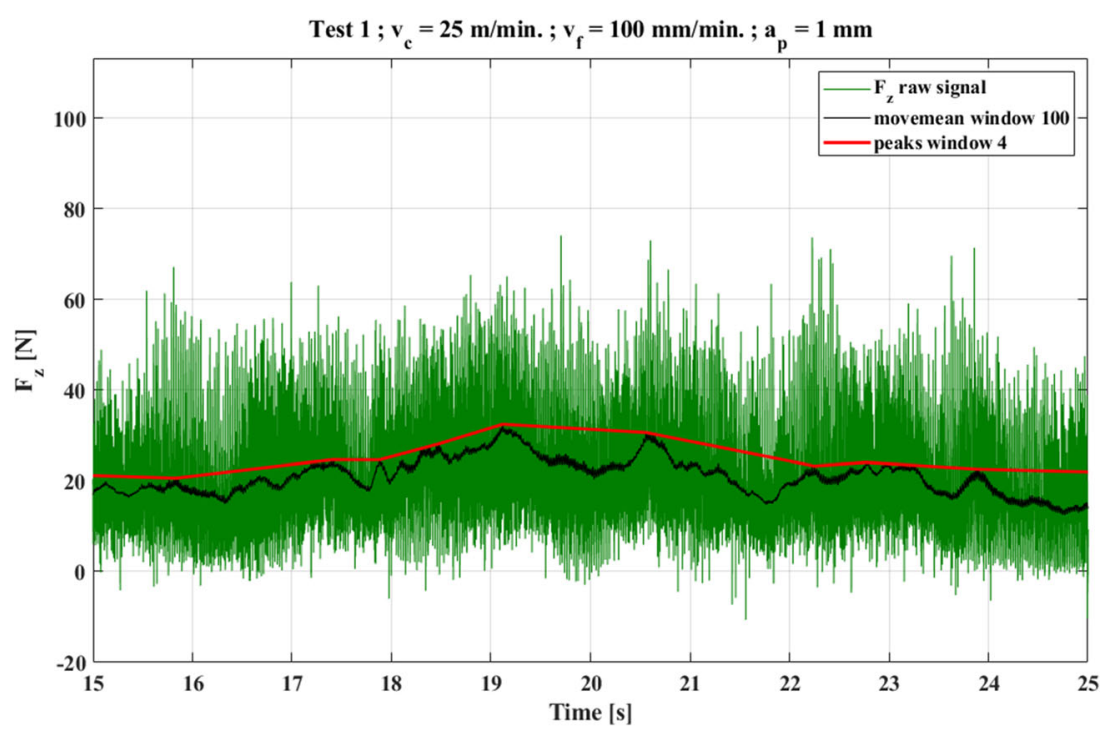

\subsubsection{Cutting forces}

Among many methods of online tool wear monitoring [21-23], the cutting forces measurements have been taken into consideration. Experiments on machining performed to determine the durability of cutting tools for uniform cutting parameters: $v_{c}=25 \mathrm{~m} / \mathrm{min} ; f=100 \mathrm{~m} / \mathrm{min} ; a_{p}=1 \mathrm{~mm}$ and $a_{e}=8 \mathrm{~mm}$ were analysed in detail taking into account the amplitude of the components of cutting force. The following figures show a comparison of the amplitude of components of cutting force for cutting distance $L=40 \mathrm{~mm}$, corresponding to the end mill cutter in sharpened state, and for cutting distance $L=3550 \mathrm{~mm}$, corresponding to the tool in which the VBI indicator was detected at the value of $0.5 \mathrm{~mm}$. Cutting tests were recorded at a frequency of $10,000 \mathrm{~Hz}$. One series of data from a cutting experiment included approximately 585,000 samples from three measurement channels $\left(F_{x}, F_{y}, F_{z}\right)$, corresponding to $58.5 \mathrm{~s}$ of data acquisition time. Due to the readability of the presented data, only the time interval corresponding to $1 \mathrm{~s}$ is shown in the diagrams in Fig. 10.

On the basis of the presented waveforms, it can be stated that the character of the waveforms of the $F_{x}$ and $F_{y}$ forces is similar, while it is shifted relative to each other in the phase. In the case of the $F_{z}$ component, the course corresponding to the sharp tool is approximately repeated from zero to maximum value (Fig. 10c). For the dulled tool, the minimum value does not return to zero but remains at around $300 \mathrm{~N}$. Therefore, components $F_{x}$ and $F_{y}$ were compared in terms of the
Fig. 8 Wear of HSS Fenes 844 A $12 \mathrm{~K}-\mathrm{N}$ end mill cutter: (a) general view, (b) uniform flank wear VB1, (c) face wear (crater and cutting edge loss), (d) nonuniform flank wear VB2
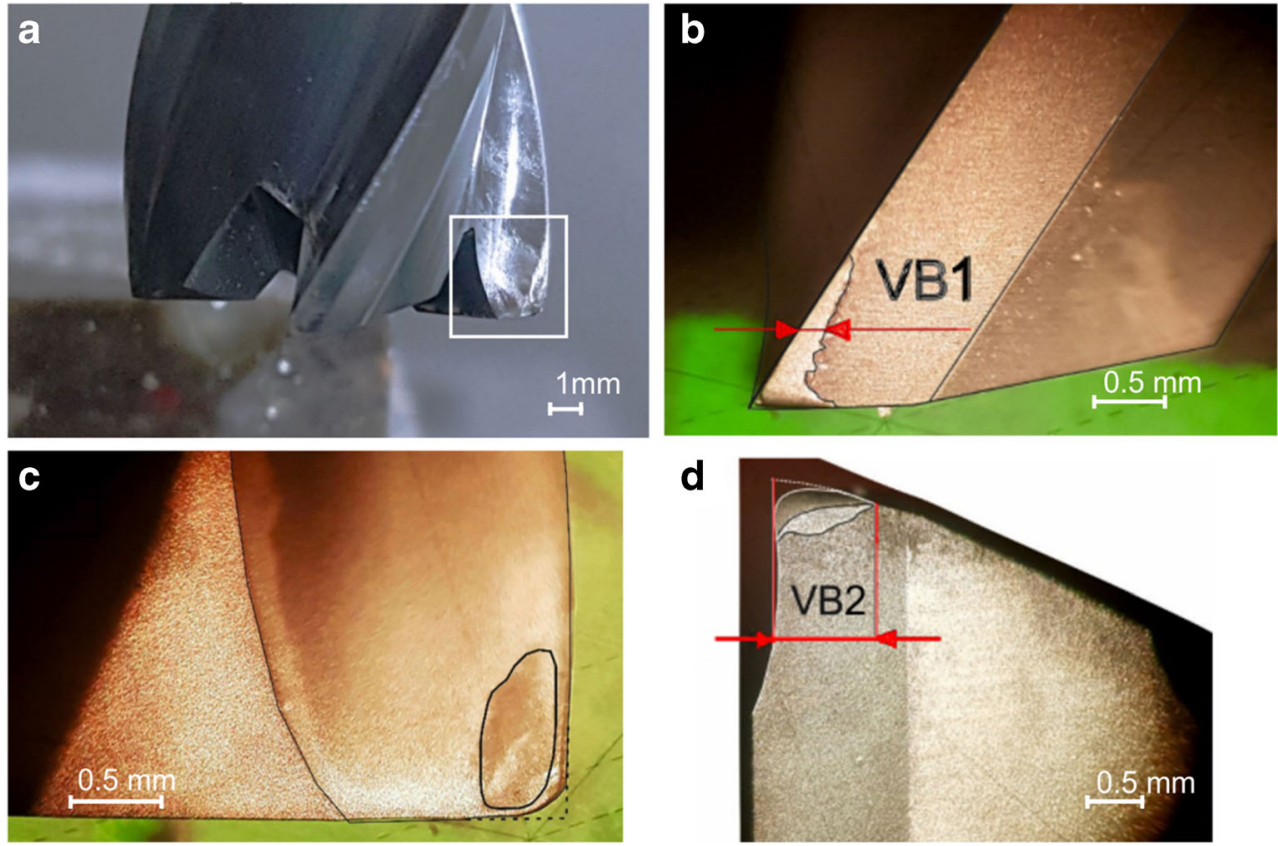

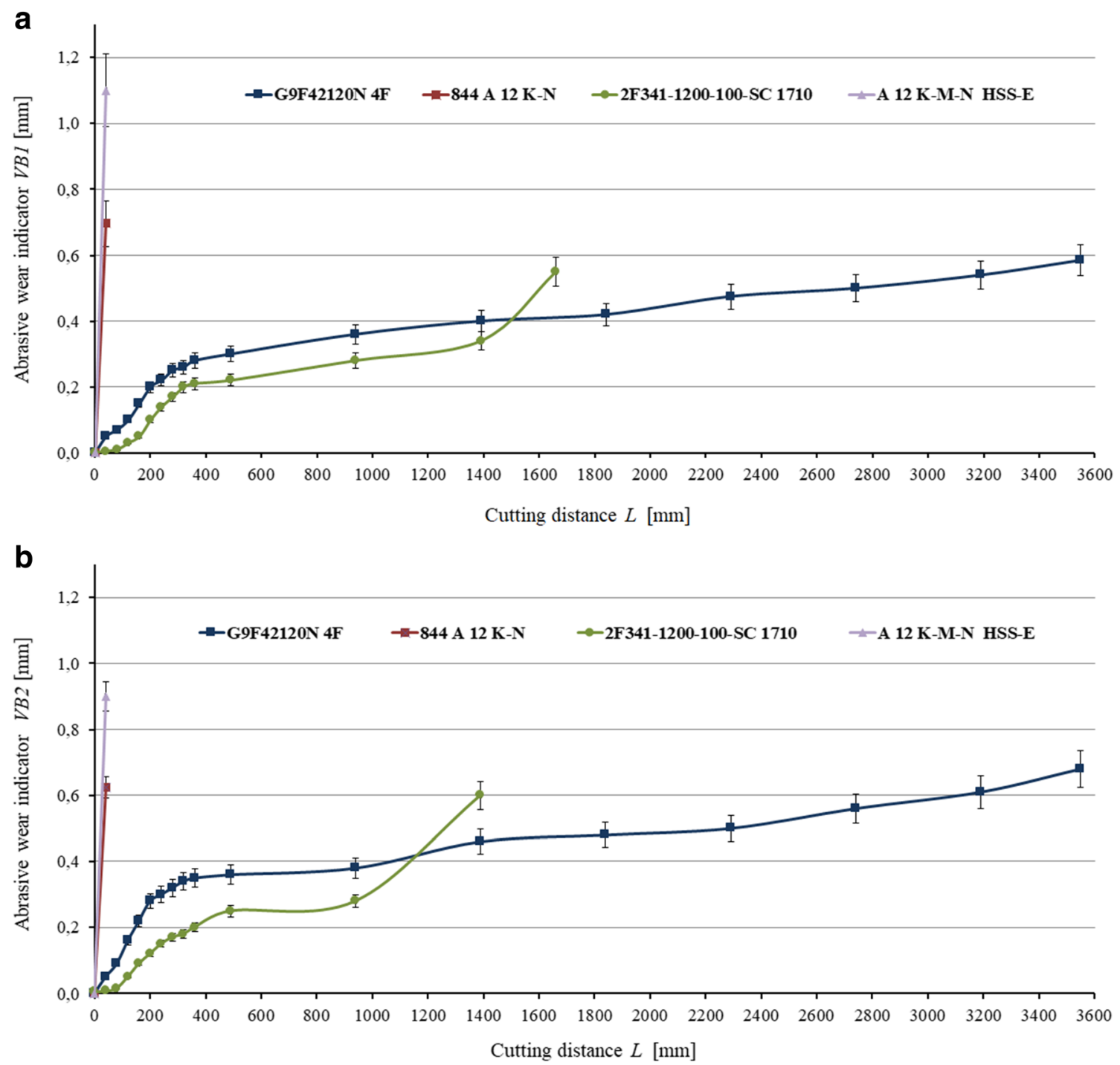

Fig. 9 Relationship between tool wear and cutting distance $L$ : (a) $V B 1$ abrasive wear indicator, (b) $V B 2$ abrasive wear indicator

amplitude of the forces, while component $F_{z}$ was compared in terms of maximum values. The results of the comparison are presented in Fig. 10d. The waveforms presented in Fig. 10 show that from the commencement of work to reaching the $V B 1$ criterion value at $0.5 \mathrm{~mm}$, the amplitude of the $F_{x}$ component force increased by $564 \%$, that of the $F_{y}$ component force by $351 \%$, and the maximum value of the $F_{z}$ component force increased by $1691 \%$. Thus, the increase in the $F_{z}$ component force was the largest, which suggests much greater intensive wear at the corners and cutting edges on the face flank of the cutter than on the cylindrical flank surface.

In relation to the tool-life analysis, the $F_{z}$ component cutting force and the $F_{a}$ resultant active cutting force in the $\mathrm{X}-\mathrm{Y}$ plane were determined.

Compared to the initial cutting tests carried out, it was also determined that the cutting force measurements are characterized by considerable arbitrariness in subsequent tool-life tests. The variable and random nature of the loads acting on the tool result from the different amounts and size of the aggregate grains contained in different areas of the machined sample. In order to analyse these forces reliably and reduce the impact of material inhomogeneity, special software has been developed to calculate the average values of recorded signals.

The procedure employed for determining the mean values of analysed component force signals consists of detecting the maximum values recorded during one revolution of the end mill cutter in the assumed interval of time and calculating the average value from the detected maxima. A fixed time interval was assumed for all machining tests equal to $25 \mathrm{~s}$. An example of the course of the component cutting force $F_{z}(L=2920 \mathrm{~mm})$ with the analysed range was shown in Fig. 11. Figure 12 shows the course of the maximum values of component $F_{z}$ (in red) and the determined mean value (in green) for the set range.

The cutting forces obtained in this way are characterized by a smaller spread of the force values, which greatly facilitates their subsequent analysis and prediction of the wear rate of the end 

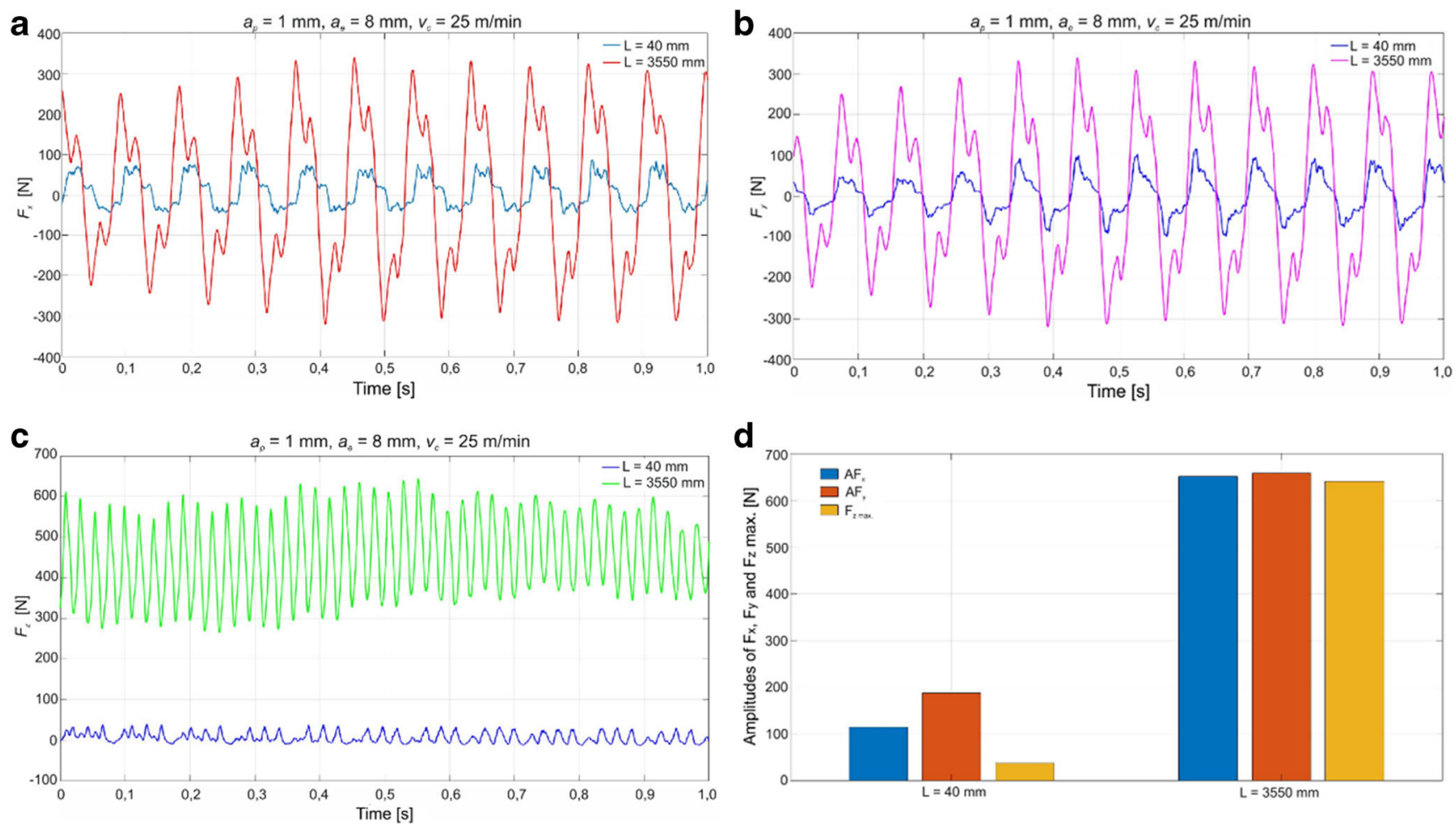

Fig. 10 Amplitude of component cutting force: $(\mathbf{a}) \mathrm{F}_{\mathrm{x}},(\mathbf{b}) \mathrm{F}_{\mathrm{y}},(\mathbf{c}) \mathrm{F}_{\mathrm{z}}$, (d) the effect of end mill cutter wear based on a comparison of the amplitudes $\mathrm{F}_{\mathrm{x}}$ and $\mathrm{F}_{\mathrm{y}}$ and the maximum values of the component cutting force $\mathrm{F}_{\mathrm{z}}$

mill cutters. Figures 13 and 14 show the courses of the resultant cutting force $F_{a}$ and the component cutting force $F_{z}$, respectively.

The highest values of cutting force occurred for end mill cutters made of high-speed steel (844 A $12 \mathrm{~K}-\mathrm{N}$ and A $12 \mathrm{~K}$ M-N HSS-E). The lowest cutting force values, however, were obtained for a cemented carbide cutter NC Mill G9F42120N 4F with protective coating. The lower cutting force for the cemented carbide tools is the result of protective coatings. Both tools have different types of protective coatings and different geometries, mainly the sharp corner and rounded corner. It can be said that sharp geometry is better for milling polymer concrete compared to a tool with a rounding radius.

Further, faster wear of the cutting edges results in increased tool vibrations [43] and variations in the cutting force, which translates into deterioration of the geometrical parameters of the machined surface. For this reason, in addition to measuring the components of the cutting force, the cutting force variations were also determined. There are many statistical features that can describe the variability or non-stationarity of the cutting force [21, 23, 44]. The standard deviation of the $F_{z}$ component signal and the resultant $F_{a}$ milling force was used for this purpose. The standard deviation describes how widely the signal values are scattered around its mean. This parameter is described by the following relationship:

$\sigma(F)=\sqrt{\frac{1}{n-1} \sum_{i=1}^{n}(F i-\bar{F})^{2}}$

where:

$\mathrm{n}$ - the number of elements in the registered time series

$\bar{F}$ - the mean value of force calculated for the analysed time interval

Figures 15 and 16 show changes in the standard deviation for the $F_{a}$ force and $F_{z}$ component, respectively. As before, the largest increase in standard deviation was registered for end mill cutters made of high-speed steel, i.e. 844 A 12 K-N and A

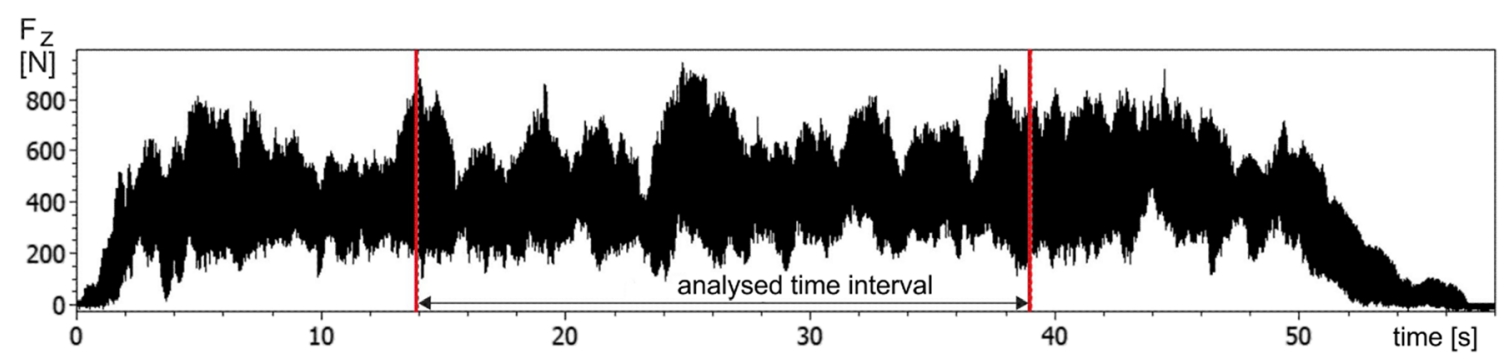

Fig. 11 The course of component force $\mathrm{F}_{\mathrm{z}}$ changes of the cutting force with the analysed time interval 


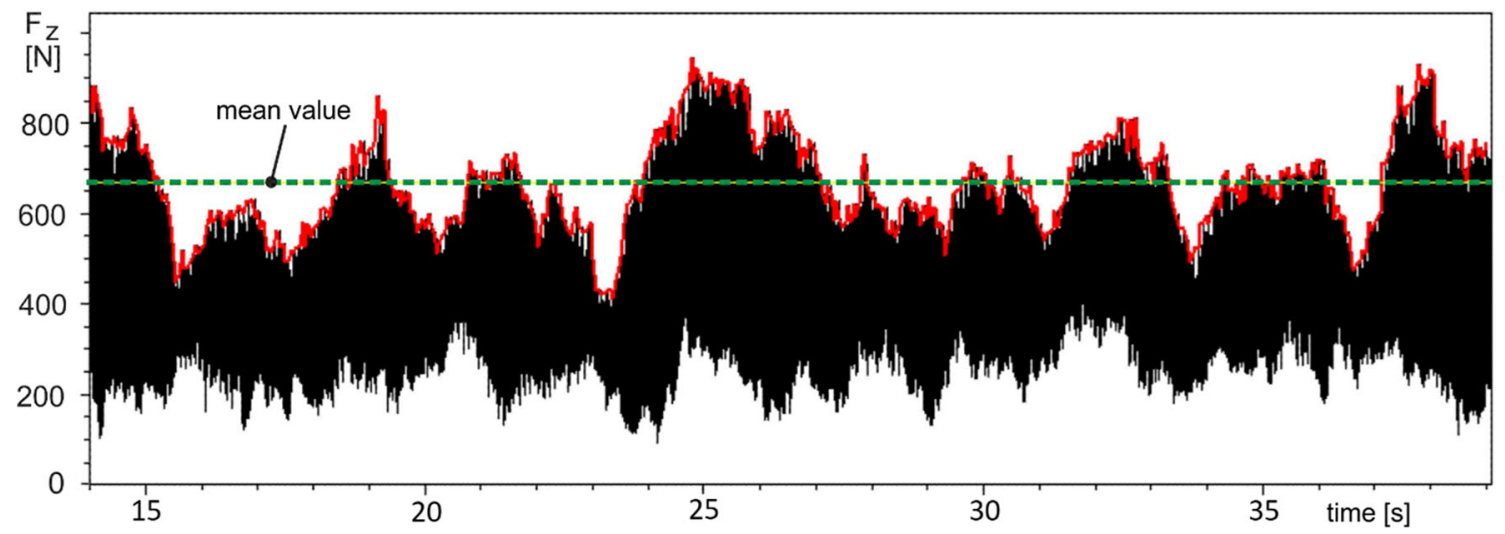

Fig. 12 The signal of the component cutting force $\mathrm{F}_{\mathrm{z}}$ in the analysed time interval and the determined mean line (in green) of the instantaneous maximum force values (in red) per one revolution of the milling cutter

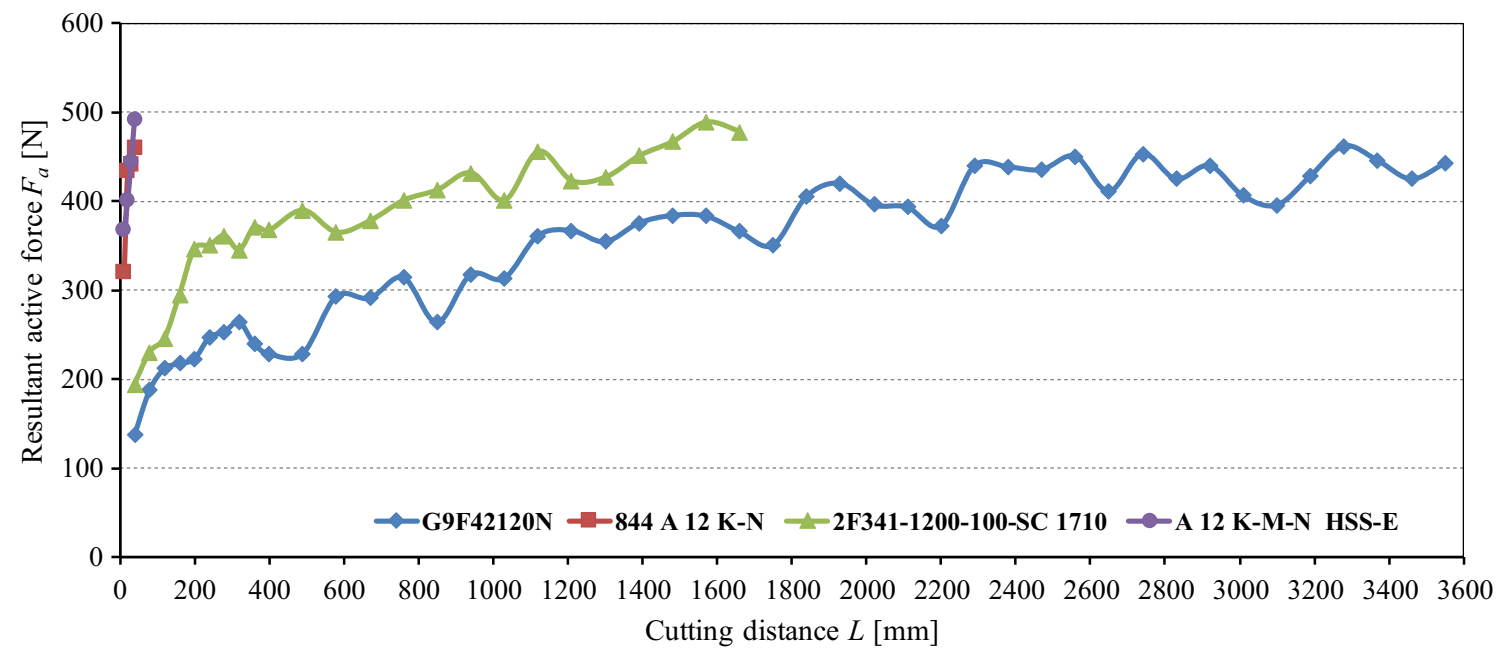

Fig. 13 Changes of resultant cutting force $F_{a}$ for individual end mill cutters

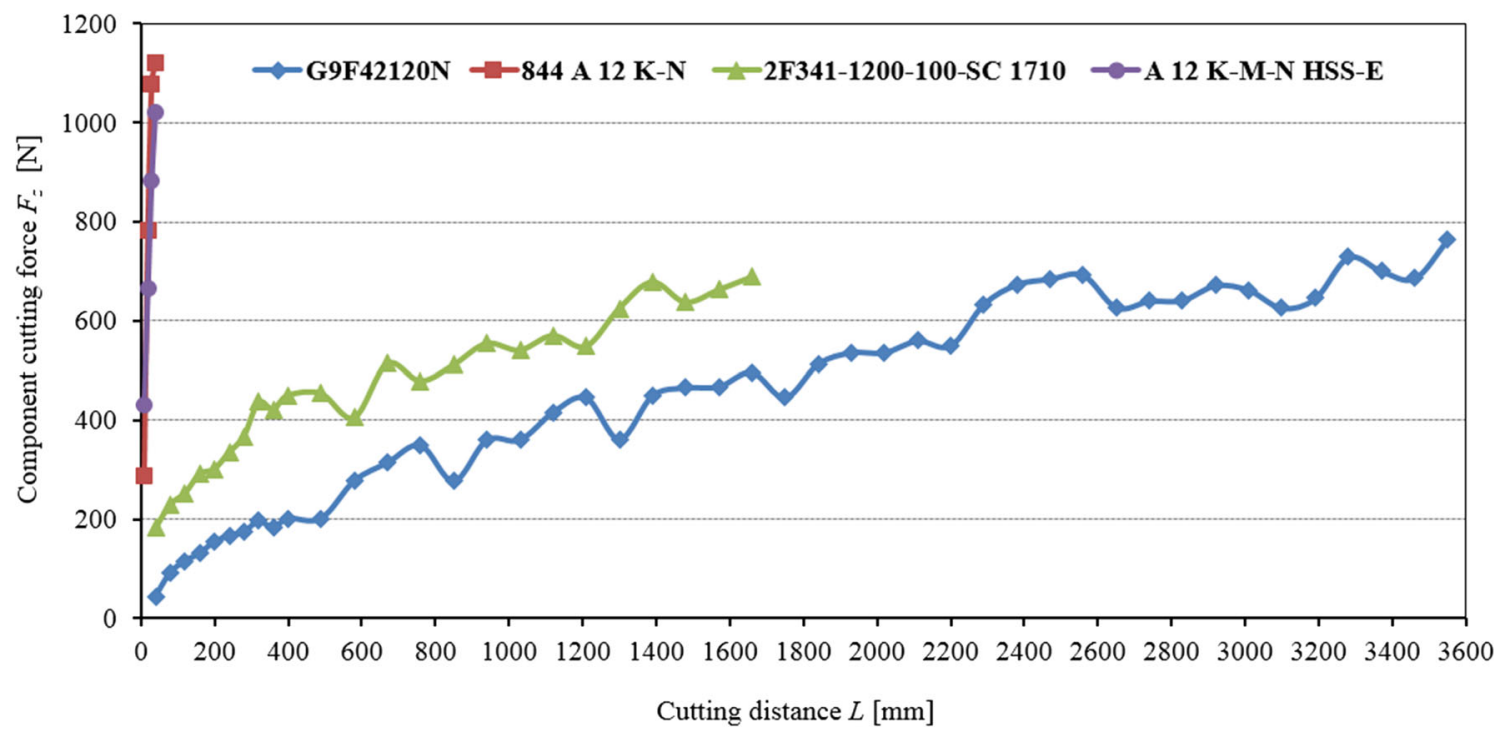

Fig. 14 Changes of component cutting force $F_{z}$ for individual end mill cutters 


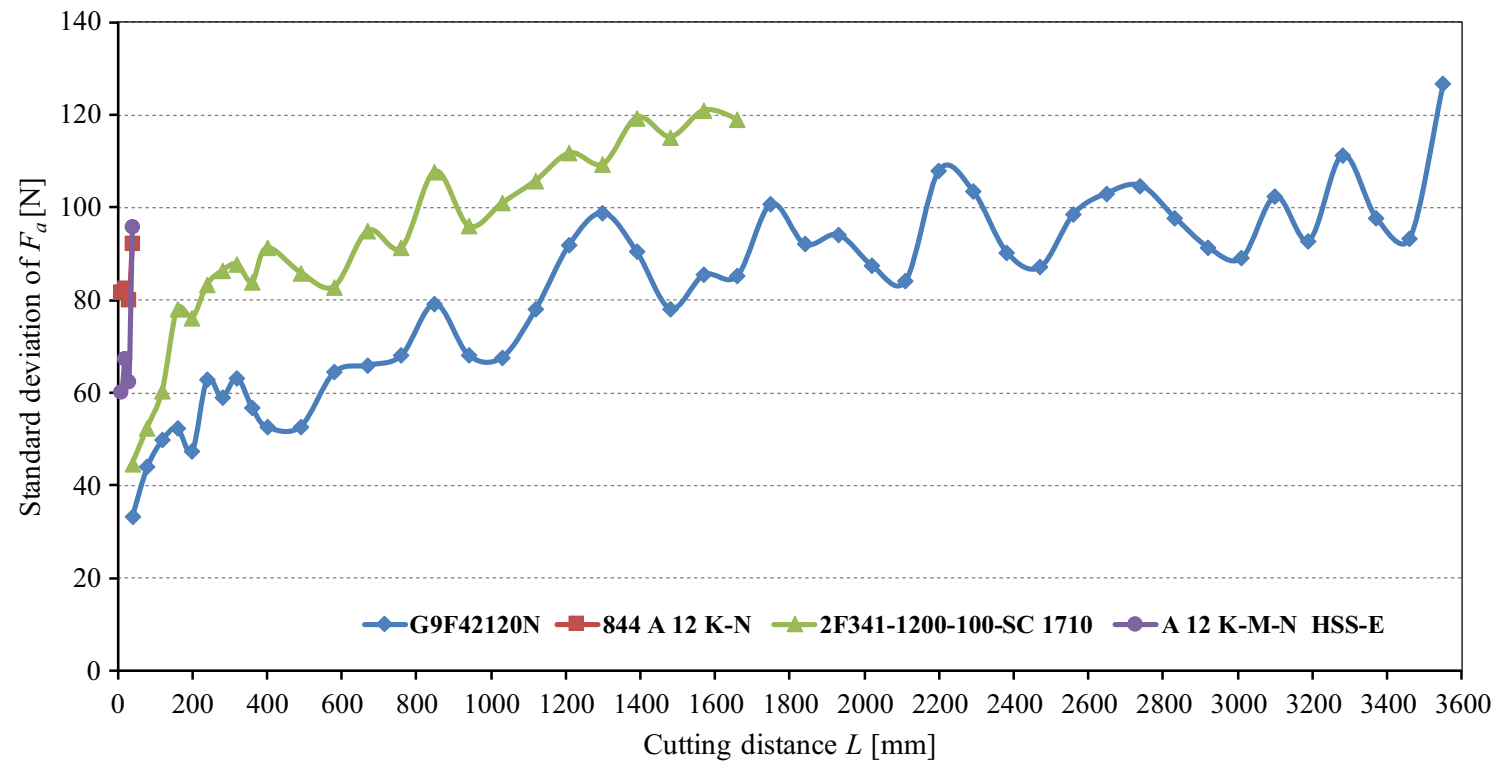

Fig. 15 Relationship between the standard deviation of resultant cutting force $F_{a}$ for individual end mill cutters and cutting distance $L$

12 K-M-N HSS-E. The smallest increase in standard deviation, however, was recorded for 2F341-1200-100-SC 1710 with coating and for the cemented carbide end mill cutter NC Mill G9F42120N 4F with coating.

\subsubsection{Polymer concrete surface roughness}

The surface roughness is influenced by many factors, including the material, manufacturing quality, the geometry of the cutting tool, the properties of the workpiece and the technological parameters used. Among the technological parameters, the most influential for surface quality is table feed rate $v_{f}$ and to a lesser extent cutting speed $v_{c}[45]$.
Surface roughness parameters $R a$ and $R z$ were measured during the tests. The relationship between $R a$ and $R z$ and cutting distance $L$ for individual end mill cutters is presented in Fig. 17a, b, respectively. The quality of the surface, as expected, deteriorates with the increase of abrasive wear of end mill cutters. The worst surface quality was obtained for high-speed steel cutters (844 A $12 \mathrm{~K}-\mathrm{N}$ and A $12 \mathrm{~K}-\mathrm{M}-\mathrm{N}$ HSS-E).

For both cemented carbide end mill cutters, the quality of the machined surface of the workpiece was similar. When the Sandvick Coromant 2F341-1200-100-SC 1710 end mill cutter begins to crumble, the surface quality deteriorates significantly. It should be emphasized that despite the significant level of wear of the tool's cutting edges, defined by the VBI and $V B 2$ indicators, the surface roughness parameters

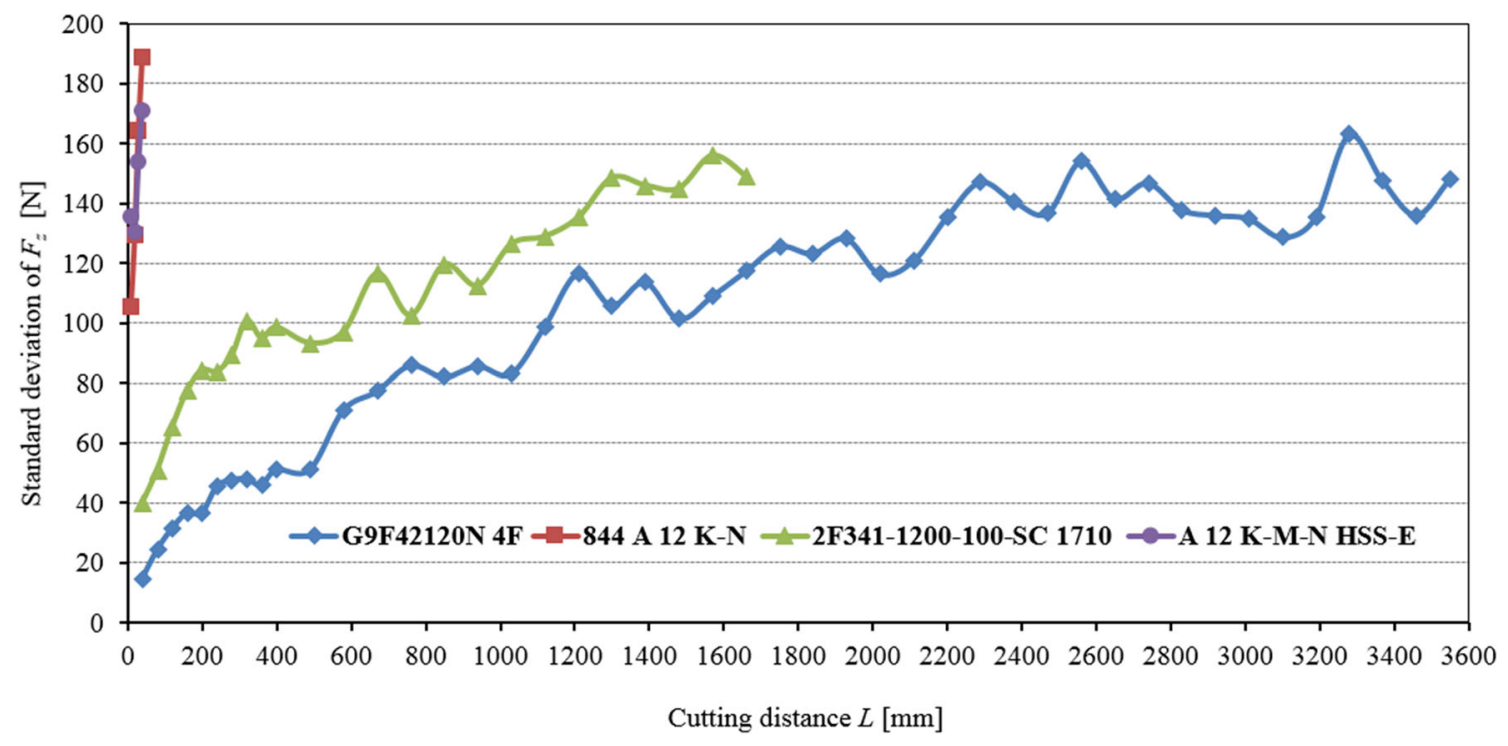

Fig. 16 Relationship between the standard deviation of component cutting force $F_{z}$ for individual end mill cutters and cutting distance $L$ 

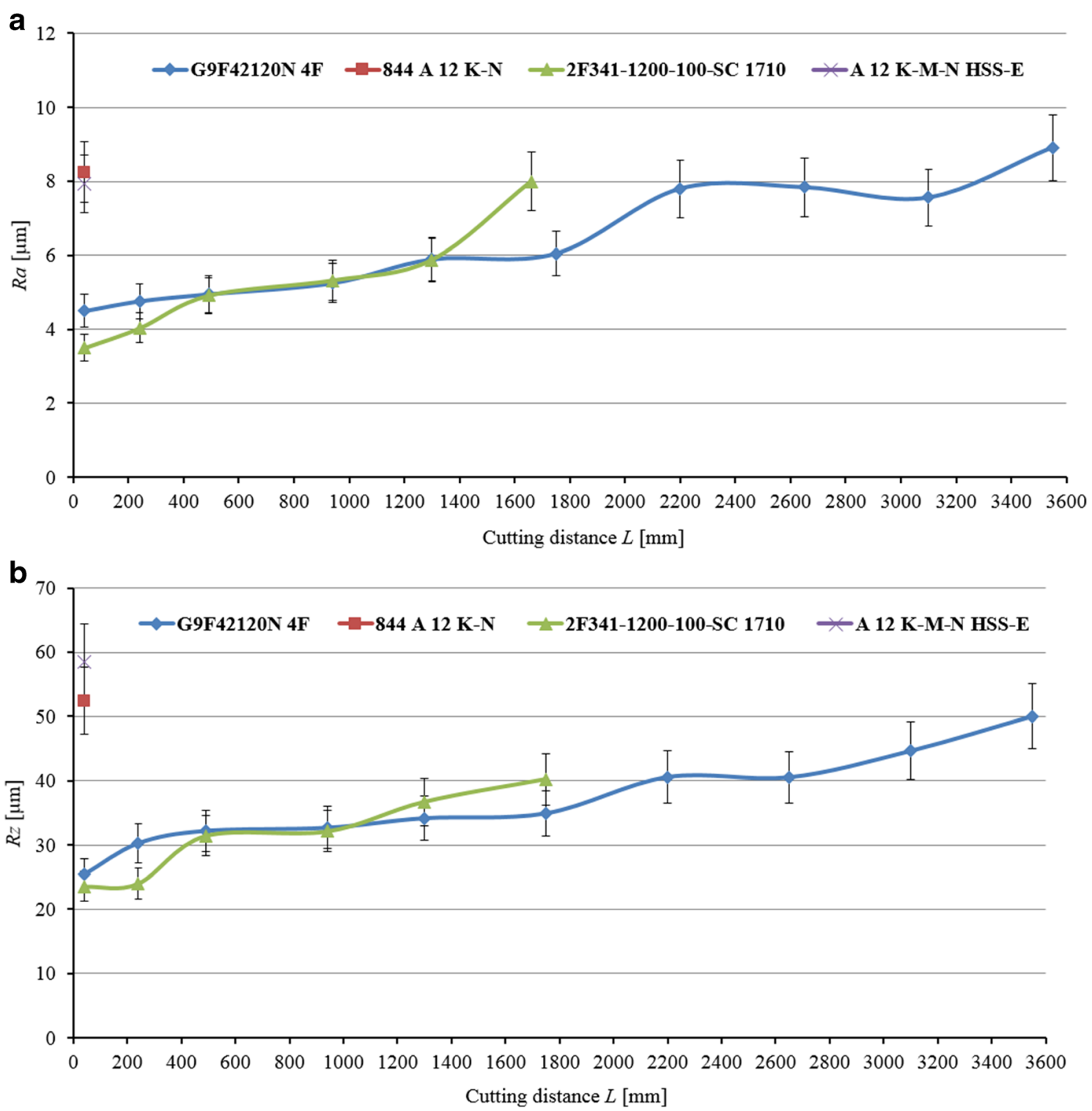

Fig. 17 Relationship between surface roughness parameters and cutting distance for individual end mill cutters: (a) $R a$, (b) $R z$

Fig. 18 Dependence of cutting force components $\mathrm{Fz}$ and $\mathrm{Fa}$ on the tool wear parameters $V B$
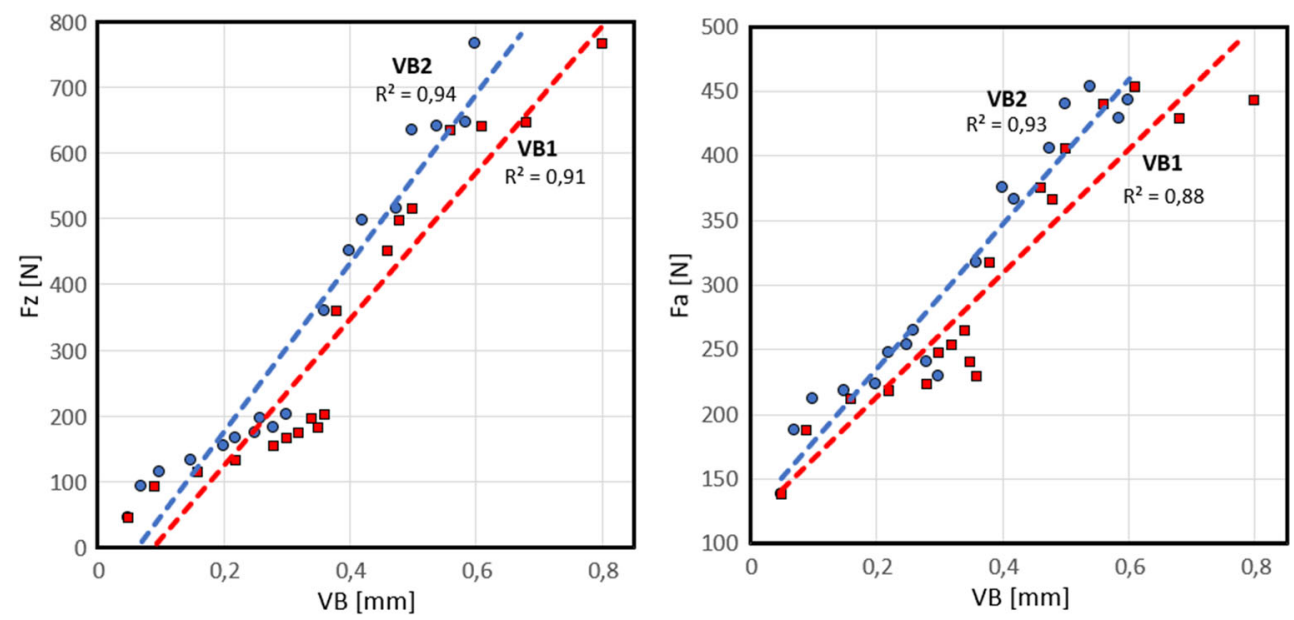
Fig. 19 Dependence of part surface roughness parameters $R a$ and $R z$ on the tool wear parameters $V B$

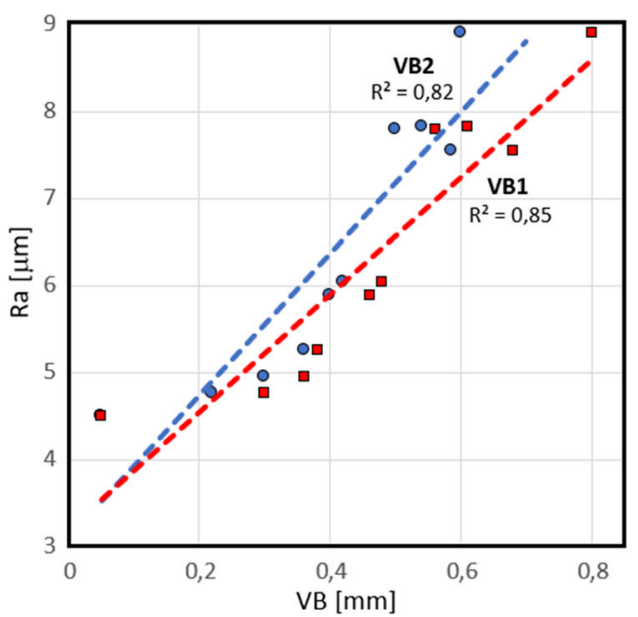

observed at cutting distance $L=1750 \mathrm{~mm}$ for the NC Mill G9F42120N 4F end mill cutter changes slightly. These changes are at the level of $1 \mu \mathrm{m}$. At a later stage, surface roughness deteriorates significantly.

The relationships between the tool wear parameters $V B$ and the resulting cutting force components $F z$ and $F a$, as well as part surface roughness parameters $R a$ and $R z$, are shown in Figs. 18 and 19, respectively. In all cases, the coefficient of determination $R^{2}$ between tool wear and cutting force components, as well as part surface roughness parameters, is greater than 0.8 which confirms the possibility of diagnosing tool wear based on measurements of these force components. It confirms that use of these force components for the assessment of tool wear during prelimiminary test presented in Chapter 4.1.
In addition, it should be noted that the standard deviation waveforms (Figs. 15 and 16) are well correlated with changes in the $R a$ and $R z$ parameters of the machined surface. Therefore, the standard deviation of the resultant cutting force can also be used to predict surface quality as part of the cutting process diagnostics system.

Comparative photos of end mill cutters wear are shown in Fig. 20.

It should be noted that end mill cutter NC Mill G9F42120N 4F (Fig. 20c) cut the longest distance $L=3550 \mathrm{~mm}$ with the smallest wear. Sandvick Coromant 2F341-1200-100-SC 1710 (Fig. 20d) had cut a distance of $L=1750 \mathrm{~mm}$ when the values of wear indicators $V B 1$ and $V B 2$ exceeded the wear limit. End mill cutters HSS Fenes 844 A12K-N (Fig. 20a) and Dolfamex A12 K-M-N HSS-E (Fig. 20b) exceeded the wear limit after a cutting distance of $L=40 \mathrm{~mm}$.
Fig. 20 Comparison of end mill cutters wear: (a) HSS Fenes 844 A12K-N, (b) Dolfamex A12 KM-N HSS-E, (c) NC Mill G9F42120N 4F, (d) Sandvick Coromant 2F341-1200-100-SC 1710
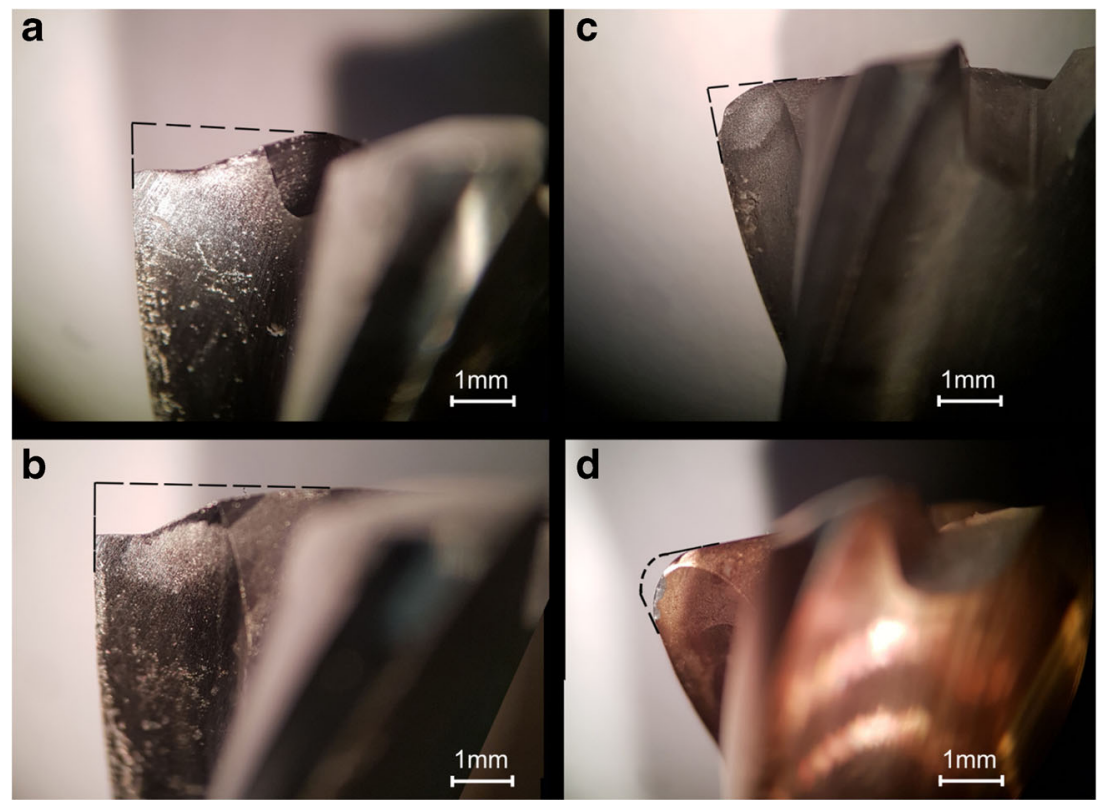


\section{Conclusions}

The paper presented the results of investigations in the machinability of a mineral cast material during milling. The impact of four types of end mill cutters and different machining conditions on cutting force, tool-life and selected surface roughness parameters were tested. The research allowed the formulation of the following conclusions:

1. Tools made of high-speed steel should not be used for machining mineral casts, as they exhibited the highest intensity of tool wear. The rapid loss of machinability of these tools leads to a rapid increase in cutting force and the roughness of the machined surface. In addition, the high values and variance of the cutting force during machining may adversely affect the durability of the machine components.

2. The machining parameters have a significant impact on the values of cutting force components $F_{x}, F_{y}$ and $F_{z}$. As a result of the experimental tests carried out, the following convenient milling parameters for polymer concrete were determined:

- Cutting speed $v_{c}=25 \mathrm{~m} / \mathrm{min}$.

- Table feed $v_{f}=100 \mathrm{~mm} / \mathrm{min}$.

- Axial depth of cut $a_{p}=1 \mathrm{~mm}$.

- Radial depth of cut $a_{e}=8 \mathrm{~mm}$.

3. The highest durability for a tool was obtained for the monolithic cemented carbide cutter with coating NC Mill G9F42120N 4F. In this case, the cutting distance reached $L=3550 \mathrm{~mm}$.

4. The values of surface roughness parameters are comparable for both cemented carbide end mill cutters.

5. Despite the wear of cemented carbide cutters, changes in the surface roughness parameters are relatively small between the beginning and end of the machining process.

In conclusion, from an economic point of view, cemented carbide end mill cutters with coatings seem to be the most appropriate choice for the machining of mineral cast materials.

Open Access This article is licensed under a Creative Commons Attribution 4.0 International License, which permits use, sharing, adaptation, distribution and reproduction in any medium or format, as long as you give appropriate credit to the original author(s) and the source, provide a link to the Creative Commons licence, and indicate if changes were made. The images or other third party material in this article are included in the article's Creative Commons licence, unless indicated otherwise in a credit line to the material. If material is not included in the article's Creative Commons licence and your intended use is not permitted by statutory regulation or exceeds the permitted use, you will need to obtain permission directly from the copyright holder. To view a copy of this licence, visit http://creativecommons.org/licenses/by/4.0/.

\section{References}

1. Ferdous W, Manalo A, Wong H, Abousnina R, AlAjarmeh O, Zhuge Y, Schubel P (2020) Optimal design for epoxy polymer concrete based on mechanical properties and durability aspects. Constr Build Mater 232:117229. https://doi.org/10.1016/j. conbuildmat.2019.117229

2. Hameed A, Hamza M (2019) Characteristics of polymer concrete produced from wasted construction materials. Energy Procedia 157:43-50. https://doi.org/10.1016/j.egypro.2018.11.162

3. Sosoi G, Barbuta M, Serbanoiu A, Babor D, Burlacu A (2018) Wastes as aggregate substitution in polymer concrete. Procedia Manuf 22:347-351. https://doi.org/10.1016/j.promfg.2018.03.052

4. Ferdous W, Manalo A, Aravinthan T (2017) Bond behaviour of composite sandwich panel and epoxy polymer matrix: Taguchi design of experiments and theoretical predictions. Constr Build Mater 145:76-87. https://doi.org/10.1016/j.conbuildmat.2017.03.244

5. Agavriloaie L, Oprea S, Barbuta M, Luca F (2012) Characterisation of polymer concrete with epoxy polyurethane acryl matrix. Constr Build Mater 37:190-196. https://doi.org/10.1016/j.conbuildmat. 2012.07.037

6. Ferdous W, Bai Y, Almutairi A, Satasivam S, Jeske J (2018) Modular assembly of water-retaining walls using GFRP hollow profiles: components and connection performance. Compos Struct 194:1-11. https://doi.org/10.1016/j.compstruct.2018.03.074Get

7. Erbe T, Król J, Theska R (2008) Mineral casting as material for machine base-frames of precision machines. Twenty-third annual meeting of the American Society for Precision Engineering and Twelfth ICPE. Portland, Oregon

8. Bruni C, Forcellese A, Gabrielli F, Simoncini M (2007) Hard turning of an alloy steel on a machine tool with a polymer concrete bed. J Mater Process Technol 202(1-3):493-499. https://doi.org/10. 1016/j.jmatprotec.2007.10.031

9. Suh J, Lee D (2008) Design and manufacture of hybrid polymer concrete bed for high-speed CNC milling machine. Int J Mech Mater Des 4(2):113-121. https://doi.org/10.1007/s10999-0079033-3

10. Kępczak N (2019) Influence of the addition of styrene-butadiene rubber on the dynamic properties of polymer concrete for machine tool applications. Adv Mech Eng 11(7):1-11. https://doi.org/10. $1177 / 1687814019865841$

11. Uhlmann E, Kaulfersch F (2016) Process behavior of super-hard cutting materials for machining mineral cast. Procedia CIRP 41: 892-897. https://doi.org/10.1016/j.procir.2015.12.066

12. Kepczak N, Rosik R, Pawłowski W, Sikora M, Witkowski B, Bechciński G, Stachurski W (2018) The dynamics of wear of cutting inserts during turning of non-homogeneous material on the example of polymer concrete. Eksploatacja i Niezawodność Maint Reliab 20(3):478-483 https://doi.org/10.17531/ein.2018.3. 18

13. Kępczak N, Rosik R (2016) An effect of depth of cut during grinding on the mineral cast surface roughness. Mechanik 8-9(2016): 1050-1051 https://doi.org/10.17814/mechanik.2016.8-9.242

14. Pawłowski W (2013) Dynamic model of oscillation-assisted cylindrical plunge grinding with chatter. J Manuf Sci Eng 135(5): 051010-051010-6. https://doi.org/10.1115/1.4024819

15. Shamray S, Daneshi A, Azrhoushang B (2016) High efficiency, high speed grinding of a composite material consisting of polymer concrete and steel structures. Procedia CIRP 46:607-610. https:// doi.org/10.1016/j.procir.2016.03.201

16. Wittbrodt $\mathrm{P}$ (2005) Life and wear of monolithic carbide mills. Eksploatacja i Niezawodność - Maint and Reliab 27(3):1-12

17. Kuczmaszewski J, Pieśko P (2014) Wear of milling cutters resulting from high silicon aluminium alloy cast AlSi21CuNi machining. Eksploatacja i Niezawodność - Maint Reliab 16(1):37-41 
18. Cichosz P (2007) Narzędzia skrawające (Cutting tools). Wydawnictwa Naukowo-Techniczne, Warszawa

19. Karandikar J, Mcleay T, Turner S, Schmitz T (2015) Tool wear monitoring using naïve Bayes classifiers. Int J Adv Manuf Technol 77(9-12):1613-1626. https://doi.org/10.1007/s00170014-6560-6

20. Rehorn A, Jiang J, Orban P (2005) State-of-the-art methods and results in tool condition monitoring: a review. Int J Adv Manuf Technol 26(7-8):693-710. https://doi.org/10.1007/s00170-0042038-2

21. Li X (2002) A brief review: acoustic emission method for tool wear monitoring during turning. Int J Mach Tools Manuf 42(2):157-165. https://doi.org/10.1016/S0890-6955(01)00108-0

22. Zhou Y, Xue W (2018) Review of tool condition monitoring methods in milling processes. Int J Adv Manuf Technol 96:25092523. https://doi.org/10.1007/s00170-018-1768-5

23. Ahmed Y, Alam M, Arif A, Veldhuis S (2019) Use of acoustic emission and cutting force signals to monitor built-up edge formation in stainless steel turning. Int J Adv Manuf Technol 103:22572276. https://doi.org/10.1007/s00170-019-03607-3

24. Paiva J, Torres R, Amorim F, Covelli D, Tauhiduzzaman M, Veldhuis S, Dosbaeva G, Fox-Rabinovich G (2017) Frictional and wear performance of hard coatings during machining of superduplex stainless steel. Int J Adv Manuf Technol 92:423432. https://doi.org/10.1007/s00170-017-0141-4

25. Javed K, Gouriveau R, Li X, Zerhouni N (2016) Tool wear monitoring and prognostics challenges: a comparison of connectionist methods toward an adaptive ensemble model. J Intell Manuf 30(4): 1-18. https://doi.org/10.1007/s10845-016-1221-2

26. Nouri M, Fussell B, Ziniti B, Linder E (2015) Real-time tool wear monitoring in milling using a cutting condition independent method. Int J Mach Tools Manuf 89:1-13. https://doi.org/10.1016/j. ijmachtools.2014.10.011

27. Azmi A (2015) Monitoring of tool wear using measured machining forces and neuro-fuzzy modeling approaches during machining of GFRP composites. Adv Eng Softw 82:53-64. https://doi.org/10. 1016/j.advengsoft.2014.12.010

28. Zhang H, Zhao J, Wang F, Li A (2015) Cutting forces and tool failure in high-speed milling of titanium alloy tc 21 with coated carbide tools. J Eng Manuf 229(1):20-27. https://doi.org/10.1177/ 0954405414526578

29. Wang M, Wang J (2012) CHMM for tool condition monitoring and remaining useful life prediction. Int J Adv Manuf Technol 59(5-8): 463-471. https://doi.org/10.1007/s00170-011-3536-7

30. Huang P, Ma C, Kuo C (2015) A PNN self-learning tool breakage detection system in end milling operations. Appl Soft Comput 37: 114-124. https://doi.org/10.1016/j.asoc.2015.08.019

31. Kaya B, Oysu C, Ertunc H (2011) Force-torque based on-line tool wear estimation system for CNC milling of Inconel 718 using neural networks. Adv Eng Softw 42(3):76-84. https://doi.org/10.1016/ j.advengsoft.2010.12.002

32. Prickett P, Johns C (1999) An overview of approaches to end milling tool monitoring. Int J Mach Tools Manuf 39(1):105-122. https://doi.org/10.1016/S0890-6955(98)00020-0
33. Koike R, Ohnishi K, Aoyama T (2016) A sensorless approach for tool fracture detection in milling by integrating multi-axial servo information. CIRP Ann Manuf Technol 65(1):385-388. https://doi. org/10.1016/j.cirp.2016.04.101

34. Ghani J, Rizal M, Nuawi M, Ghazali M, Haron C (2011) Monitoring online cutting tool wear using low-cost technique and user-friendly GUI. Wear 271(9-10):2619-2624. https://doi.org/10. 1016/j.wear.2011.01.038

35. Stavropoulos P, Papacharalampopoulos A, Vasiliadis E, Chryssolouris G (2016) Tool wear predictability estimation in milling based on multi-sensorial data. Int J Adv Manuf Technol 82(14):509-521. https://doi.org/10.1007/s00170-015-7317-6

36. EPUMENT 140-5 GB https://www.rampf-group.com/en/productssolutions/chemical/do-it-yourself-mineral-casting/ Accessed 26 March 2019

37. Kistler - Analyzing and optimizing cutting processes - Cutting force measurements in research and development. https://www. kistler.com $/$ type $=669 \&$ fid $=539 \&$ model $=$ download $\&$ callee $=$ frontend Accessed 30 March 2019

38. Kuczmaszewski J, Zagórski I, Zgórniak P (2016) Thermographic study of chip temperature in high-speed dry milling magnesium alloys. Manage Prod Eng Rev 7(2):86-92. https://doi.org/10. 1515/mper-2016-0020

39. ISO 8688-2:1989(en) Tool life testing in milling - Part 2: End milling. https://www.iso.org/obp/ui/\#iso:std:iso:8688:-2:ed-1:v1: en Accessed 28 March 2019

40. Lajmert P, Rusinek R, Kruszyński B (2018) Chatter identification in milling of Inconel 625 based on recurrence plot technique and Hilbert vibration decomposition. International conference on engineering vibration. MATEC web of conferences, 2018; vol. 148. $\mathrm{https} / / /$ doi.org/10.1051/matecconf/201814809003

41. Zgórniak P, Grdulska A (2012) Investigation of temperature distribution during milling process of AZ91HP magnesium alloys. Mech Mech Eng 16(1):33-40

42. Zgórniak P, Stachurski W, Ostrowski D (2016) Application of thermographic measurements for the determination of the impact of selected cutting parameters on temperature in the workpiece during milling process. Strojniški vestnik - J Mech Eng 62(11):657-664. https://doi.org/10.5545/sv-jme.2015.3259

43. Schmitz TL, Smith KS (2019) Machining dynamics. Springer International Publishing. https://doi.org/10.1007/978-3-31993707-6

44. Lajmert P, Sikora M, Kruszyński B, Ostrowski D (2017) Application of principal component analysis and decision trees in diagnostics of cylindrical plunge grinding process. Adv Manuf: 707-716. https://doi.org/10.1007/978-3-319-68619-6_68

45. Haja Syeddu Masooth P, Jayakumar V, Bharathiraja G (2019) Experimental investigation on surface roughness in CNC end milling process by uncoated and TiAlN coated carbide end mill under dry conditions. Mater Today Proc. https://doi.org/10.1016/j.matpr. 2019.10.036

Publisher's note Springer Nature remains neutral with regard to jurisdictional claims in published maps and institutional affiliations. 